\title{
Kollokasies: 'n Leksikografiese perspektief
}

\section{A.E. van Niekerk, Buro van die Woordeboek van die Afrikaanse Taal}

Abstract: Collocations: A Lexicographical Perspective. It is the responsibility of the lexicographer to give an account of collocations in a monolingual explanatory dictionary. Collocations are unpredictable conventionalized sintagmatic combinations and could therefore only be acquired through learning. The native speaker will not necessarily be able to anticipate a particular collocational pattern intuitively. In accordance with the cognitive approach a clear distinction can not be drawn between free phrases, collocations and idioms. The lexicographer should nevertheless be able to justify his distinction within the context of the dictionary. The needs of the dictionary user should always be adhered to. The lexicographical function of collocations is different from, but supplementary to, those of the definition and the examples respectively. Therefore collocations have a unique position within the linear microstructure which neither the definition nor the examples can replace. The semantic differentiation between base and collocator is of little importance to the lexicographer. A collocation can potentially be included in the article of either the base or the collocator. The detection of collocational patterns can be simplified by the use of a computer. Thus the task of the lexicographer will be eased considerably. In supplying collocational information the lexicographer gives substance and structure to the dictionary article. The user will, in addition, benefit from a complete, well-founded treatment of collocations.

Keywords: LEXICOGRAPHER, FREE PHRASES, COLLOCATIONS, IDIOMS, DEFINITION, EXAMPLES, ARTICLE, USER, BASE, COLLOCATOR

Opsomming: 'n Eentalige, verklarende woordeboek moet van kollokasies rekenskap gee. As onvoorspelbare, gekonvensionaliseerde sintagnatiese verbindinge moet kollokasies aangeleer word. Die moedertaalspreker sal daarom in die reël nie 'n bepaalde kollokatiewe patroon in tuitief kan antisipeer nie. Die leksikogr aaf het egter in dié verband geensins 'n maklike taak nie. 'n Absolute skeiding tussen vrye verbindinge, kollokasies en idiome is, veral in die lig van die kognitiewe benadering, nue moontlik nie. Die leksikograaf moet nietemin die skeiding wat hy maak, kan verantwoord. Die behoeftes van die gebruiker behoort altyd die deurslag te gee. Kollokasies verrig ' $n$ leksikografiese funksie wat verskillend van, maar aanvullend tot die funksie van die definiens en die voorbeeldsinne is. Die plek wat kollokasies binne die lineêre mikrostruktuur beklee, kan gevolglik nóg deur die definiens, nóg deur voorbeeldsinne gevul word. Vir die leksikograaf hou die semantiese onderskeid tussen basis en kollokator oor die algemeen nie stand nie. 'n Kollokasie $k a n$ in beginsel in die artikel van sowel 'n basis as ' $n$ kollokator ingesluit word. Die rekenaar kan met vrug ingespan word om kollokatiewe patrone te isoleer en die leksikograaf se taak te vergemaklik. Kollokasies maak dit vir die leksikograaf moontlik om op 'n nie-arbitrêre basis groter inhoud en struktuur aan die woordeboekartikel te verleen. Daarbenewens sal die gebruiker baat vind by 'n volledige, verantwoorde hantering van kollokasies. 
Sleutelwoorde: LEKSIKOGRAAF, VRYE VERBINDINGS, KOLLOKASIES, IDIOME, DEFINIENS, VOORBEELDSINNE, ARTIKEL, GEBRUIKER, BASIS, KOLLOKATOR

\section{Inleiding}

Taal is funksioneel omdat dit gebruik word. Gevolglik is ' $n$ voldoende insig in die taalstruktuur alleen moontlik wanneer taalgebruik bestudeer word. Taalgebruik is tradisioneel in eentalige, verklarende woordeboeke met behulp van kollokasies en voorbeeldsinne geillustreer. Vir die praktiserende leksikograaf bly dit 'n uitdaging om kollokasies en voorbeeldsinne doeltreffend aan te wend.

Die bespreking in afdeling 2 hieronder konsentreer op die nut wat kollokasies met betrekking tot gebruiksleiding in 'n eentalige, verklarende woordeboek kan hê. Regverdiging vir die leksikografiese insluiting van hierdie tipe sintagmatiese verbindinge word in die aard en wese van kollokasies sélf gesoek.

In afdeling 3 word die semantiese verskille tussen vrye verbindinge, kollokasies en idiome aangeraak, maar terselfdertyd gerelativeer binne die raamwerk van die kognitiewe semantiek. Die implikasie wat sodanige relativering vir die leksikografiese praktyk inhou, word uitgespel.

Die plek wat kollokasies binne die lineêre mikrostruktuur, oftewel die artikelstruktuur beklee, word in afdeling 4 behandel, en in die proses word die funksionaliteit van kollokasies met dié van die definiens enersyds en voorbeeldsinne andersyds, gekontrasteer.

Ten slotte word daar in afdeling 5 uitsluitsel gegee oor hoe en waar kollokasies in 'n woordeboek geplaas behoort te word.

Binne die raamwerk van die bogenoemde aangeleenthede word daar gepoog om bepaalde aspekte van die taalwetenskaplike literatuur oor kollokasies in leksikografiese perspektief te plaas en enkele voorstelle te doen vir 'n verantwoorde hantering van kollokasies.

\section{Regverdiging vir opname}

Die opname van kollokasies in 'n eentalige, verklarende woordeboek kan deels geregverdig word aan die hand van die volgende definisie van Gouws (1989: 227):

'"n Kollokasie is 'n (i) kombinasie van woorde wat (ii) dikwels saam gebruik word, maar wat (iii) nie 'n vaste uitdrukking is nie (iv) omdat die afsonderlike woorde se leksikale betekenis steeds gehandhaaf word en (v) die verbinding nie as 'n geleksikaliseerde betekeniseenheid optree nie." 
As (i) kombinasie van woorde gee 'n kollokasie 'n aanduiding van die verbindingspotensiaal van 'n lemma met 'n ander leksikale item of items waarmee dit in sintagmatiese verband staan. Deur verder te weerspieël dat sekere leksikale items (ii) dikwels in kombinasie met mekaar optree, gee elke kollokasie iets van natuurlike taalgebruik te kenne. Die frekwensie waarmee twee of meer leksikale items sáám voorkom, suggereer (iii) 'n bepaalde kohesie wat, soos die kohesie by vaste uitdrukkings, nie sistematies voorspelbaar is nie. Geeneen van die komponente van 'n kollokasie hoef egter (iv) sy semantiese outonomie in te boet nie. Daar is by ' $n$ kollokasie nie van 'n (v) geykte, geleksikaliseerde betekeniseenheid sprake nie en 'n kollokasie kan dus, as deursigtige verbinding, deel uitmaak van die onverklaarde voorbeeldmateriaal. Wat wel gebeur, is dat ' $n$ kollokasie deur herhaalde gebruik in 'n bepaalde konteks gekondisioneer word en met ander woorde as sintagmatiese verbinding, maar nie as betekeniseenheid nie, geyk raak.

Die kohesie tussen die leksikale items hees en stem is byvoorbeeld sodanig dat die frekwensie waarmee hees juis stem selekteer, hoër is as dié van enige ander adjektief (vergelyk eentonige, growwe, krakerige, sagte, ens.) waarmee stem in vrye verbinding staan. Die affiniteit van hees vir stem word deur taalkonvensie bepaal en is vir die moedertaalsprekers, sowel as die aanleerders van 'n betrokke taal, ewe onlogies. Kollokatiewe patrone kan alleen in die geheues van taalgebruikers vasgelê word wanneer hulle keer op keer in gesproke en geskrewe kontekste daaraan blootgestel word. In die lig hiervan is die insluiting van kollokasies in woordeboekartikels onontbeerlik.

' $n$ Ander beweegrede vir die opname van kollokasies is geleë in gevalle waar paradigmatiese leksikale betrekkinge (bv. sinonimie en antonimie) bestaan. Daar is byvoorbeeld geen logika wat die gebruiker daarop voorberei dat die leksikale item apologie met aanteken kollokeer, maar dat 'n sinoniem van eersgenoemde, naamlik verskoning, met die leksikale item maak kollokeer nie. Die vaste voorsetselverbindinge in sinonieme kollokasies soos byvoorbeeld ' $n$ hekel aan, ' $n$ renons in en ' $n$ afkeer van, maak ook deel uit van die onverklaarbare van die taalsisteem.

Eweneens is die bestaan van die kollokasie fyn spot geen waarborg dat die teenoorgestelde, te wete blatant spot, as kollokasie gemanifesteer sal word nie. Dit is die verantwoordelikheid van die leksikograaf om die gebruiker oor hierdie idiosinkrasie voor te lig. Dieselfde argument geld ook die kollokasie blatante leuen teenoor die vrye verbindinge van leuen en verskuilde, verbloemde, subtiele, ens.

Kollokasies is ook taalspesifiek, soos Aisenstadt (1981: 59) tereg opmerk. Die ekwivalente van die leksikale items wat in 'n bepaalde taal die komponente van 'n kollokasie uitmaak, hoef nie noodwendig in 'n ander taal as komponente van 'n kollokasie op te tree nie. Vergelyk byvoorbeeld die Afrikaanse kollokasie ' $n$ figuur slaan met sy Engelse ekwivalent to cut a figure. Wat in die een taal 'n kollokasie is, hoef dit nie noodwendig in 'n ander taal te wees nie. Vergelyk die Engelse kollokasie bobbed hair met die Afrikaanse kompositum polkahare, of 
die Afrikaanse kollokasie Nugter weet! met die Duitse idioom Daß weiß der Kuckuck! Die gebruiker sal dus ongetwyfeld by die aangawe van kollokasies baat.

Gesien teen die agtergrond van 'n breër konseptuele raamwerk, vertoon Gouws se definisie waarin kollokasie en vaste uitdrukking as teenpole genoem word, enigsins rigoristies. Die taalwerklikheid laat hom nie waterdig ka tegoriseer nie, soos uit die volgende paragrawe sal blyk.

\section{Die begrip "kollokasie"}

Die lukrake wyse waarop kollokasies tot dusver in verklarende Afrikaanse woordeboeke gehanteer is, is simptomaties van onder meer die onvermoë van taalkundiges om eenstemmigheid te bereik oor die begrip "kollokasie". Nasionale Woordeboek (voortaan NW) gee byvoorbeeld die verbindinge lokale kleur en lokale verdowing onverklaard as kollokasies by die toepaslike betekenisonderskeidings in die artikel van die lemma lokaal. Verklarende Handwoordeboek van die Afrikaanse Taal (voortaan HAT) hanteer die genoemde verbindinge soos uitdrukkings deur sowel lokale kleur as lokale verdowing van 'n betekenisverklaring te voorsien. Die verbinding rou bedryf word weer in NW as uitdrukking in die artikel van die lemma rou verklaar, terwyl dit in HAT onverklaard as kollokasie aangegee word. Hierdie hanteringswyse verwar die gebruiker en lei daartoe dat ' $n$ waardevolle sintagmatiese illustrasiemedium onderbenut bly.

Word die uiteenlopende sienswyses van taalkundiges wat hulle in ouer en meer resente literatuur oor kollokasies uitgelaat het, vergelyk, kan breedweg twee hoofrigtings geïsoleer word (Carstens 1992: 1).

Aan die een kant is daar die Aristoteliaanse hoofbenadering waarbinne ' $n$ rigiede kategoriale onderskeid tussen vrye verbindinge, kollokasies en idiome gehand haaf word. Aan die ander kant is daar die prototipe-benadering wat, in ooreenstemming met die beginsels van die kognitiewe semantiek, vir kollokasies as ' $n$ hibridiese linguistiese kategorie voorsiening maak. Vergelyk die bespreking waarin Carstens (1992: 1-11) die laasgenoemde benadering aan die hand van Afrikaanse voorbeeldmateriaal toelig.

Was dit moontlik om - soos die Aristoteliaanse benadering voorstel rigiede verdelings tussen vrye verbindinge, kollokasies en idiome te maak, was die leksikograaf se taak aansienlik makliker. Hy sou dan sy data meganies in die genoemde kategorieë kon indeel, ondubbelsinnig aan die gebruiker daaroor uitsluitsel kon gee en terselfdertyd kritiek van die taalkundiges kon vryspring.

Ongelukkig strook so 'n lynregte verdeling nie met die taalwerklikheid nie. Die leksikograaf moet aanvaar dat kollokasies naamlik iewers op 'n kontinuum lê waarvan vrye verbindinge en vaste uitdrukkings die uiterste, teenoorstaande pole vorm. Kollokasies sou dus nie alleen minder prototipiese vrye verbindinge nie, maar ook minder prototipiese idiome kon insluit. 
Die taaldinamika maak voorts daarvoor voorsiening dat kategoriale grense verskuifbaar is en dit is dus moontlik dat vrye verbindinge gaandeweg in kollokasies kan verander, of dat kollokasies idioomstatus kan verwerf.

Dit.is dan ook van hierdie likiditeit dat Mackin (1978: 163) getuig wanneer hy na aanleiding van proefpersone se reaksie op vraelyste waarin hulle kollokatiewe frases moes voltooi, die volgende sê:

"It emerged from this experiment that one must tread warily when dealing with 'fixed' phrases or collocations ... The extent of variation in some of the words used to complete the phrases meant that one could take nothing entirely for granted ... The language is constantly changing at the level of collocation just as much as, if not more than, at other levels."

Dit is die onbenydenswaardige taak van die leksikograaf om dié beweeglike, veranderlike struktuur tot ' $n$ vaste vorm te reduseer. Die enigste kriterium wat hy met 'n mate van sekerheid kan aanlê om die status van kollokasies binne die artikel te bepaal, is die behoeftes van die gebruiker. Kollokasies wat net so deursigtig soos vrye verbindinge is, kan onverklaard as voorbeeldmateriaal gebruik word. Kollokasies wat 'n neiging tot idioomkarakter het, en wat gevolglik vir die gebruiker interpretasieprobleme meebring, moet verkieslik saam met' $n$ verklaring opgeneem word.

\section{Mikrostrukturele ordening}

Betekenis en gebruik is nie in isolasie te bestudeer nie. Een van die leksikograaf se metodes by definiëring, is juis om die betekenisse van leksikale items te abstraheer uit 'n verskeidenheid gebruiksgevalle.

In die lig hiervan raak die verskillende sintagmatiese betrekkinge wat leksikale items binne ' $n$ bepaalde semantiese veld met mekaar aanknoop, van wesenlike belang.

De Stadler (1991: 62) onderskryf die bogenoemde standpunt wanneer hy sê dat die bestudering van leksikale betrekkinge 'n belangrike heuristiese instrument word in die soeke na groter insig in die aard van leksikale betekenis en leksikale struktuur.

Hieruit volg dat die leksikografies funksionele verskille tussen die definiens, kollokasies en voorbeeldsinne gesoek moet word in die diversiteit van sintagmatiese betrekkinge wat leksikale items met mekaar aangaan. Daar kan nie langer volstaan word met 'n simplistiese onderskeid tussen die definiens se funksie as draer van betekenisinligting enersyds en kollokasies en ander illustrasiemateriaal se funksie as draers van gebruiksinligting andersyds nie.

Vir die doel van dié bespreking is veral twee tipes sintagmatiese betrekkinge van waarde. As vertrekpunt word geneem die onderskeid wat De Stadler (1991: 64) maak tussen sintagmatiese leksikale betrekkinge en daardie sin- 
tagmatiese betrekkinge wat hul in kollokasies manifesteer.

\subsection{Kollokasie versus definiens}

'n Sintagmatiese leksikale betrekking is ' $n$ betrekking wat twee of meer leksikale items op grond van hulle betekenisse aanknoop. ' $n$ Kollokasie, daarenteen, is 'n betrekking tussen leksikale items wat nie volg uit die betekenisse van die onderskeie items nie.

As belangrikste leksikografiese middel vir die weergawe van betekenisinligting moet die definiens die betekenis of betekenisse van 'n leksikale item beskryf, soos hierdie item deur die moedertaalsprekers gebruik word.

De Stadler (1991: 77-80) illustreer aan die hand van voorbeelde uit NW en HAT hoe die leksikograaf sintagmatiese leksikale betrekkinge kan inspan om definiëring te vergemaklik.

Word ' $n$ bepaalde leksikale item by herhaling in ' $n$ sintagma saam met ' $n$ ander leksikale item gebruik, vind kondisionering met verloop van tyd plaas, en die resultaat is ' $n$ sintagmatiese leksikale assosiasie van sodanige aard dat die een leksikale item se betekenis in dié van die ander opgesluit of - om De Stadler se terminologie te gebruik - "geënkapsuleer" word.

Die betekenis van die leksikale item kok kan byvoorbeeld kwalik beskryf word, sonder om die leksikale item kos te gebruik. NW definieer kok byvoorbeeld as "persoon wat kos voorberei ..." ", terwyl die HAT-definisie só lui: "Man wat belas is met die voorbereiding van kos ..."

Dieselfde geld die leksikale items tand en kou.

Wat verder uit die leksikale pare kok $\times$ kos en tand $\times k o u$ blyk, is dat daar verskille kan bestaan ten opsigte van die mate waarin enkapsulering plaasvind. De Stadler (1991: 68-69) onderskei tussen unilaterale en bilaterale enkapsulering wat die proses van leksikografiese definiëring beduidend raak.

By kok $\mathrm{x}$ kos is die enkapsulering unilateraal; met ander woorde die betekenis van kos word in dié van kok geënkapsuleer, maar die omgekeerde vind nie plaas nie. Terwyl die betekenis van kok nie sonder gebruik van kos beskryf kan word nie, kan kos geredelik sonder gebruik van kok gedefinieer word.

In die voorbeeld tand $x$ kou vind die enkapsulering bilateraal plaas, met ander woorde die betekenis van kou word in dié van tand geënkapsuleer en omgekeerd. Hierdie bilaterale betrekking word bevestig wanneer die definiense van die betrokke leksikale items in NW en HAT nagegaan word. NW definieer tand as "benerige byt- en kouorgaan van mens en dier ...", terwyl kou se definisie lui: "maal met die tande". HAT beskryf tand as "Een van die harde, ivooragtige beentjies wat ... veral dien om kos fyn te kou ..." en kou se definisie lui: "Met die tande fyn maal".

Die voorafgaande illustreer dat die definiens hom daartoe leen om sintagmatiese leksikale betrekkinge, of dit nou unilateraal of bilateraal is, weer te gee. 
In teenstelling hiermee vergestalt 'n kollokasie 'n verwante, dog meer geykte sintagmatiese betrekking en in dié opsig vervul dit 'n funksie wat van dié van die definiens verskil, maar dit terselfdertyd komplementeer.

Wat by ' $n$ kollokasie van belang is, is dat die herhaalde optrede van ' $n$ bepaalde leksikale item in ' $n$ sintagma saam met ' $n$ ander leksikale item dermate kondisionering bewerkstellig dat die sintagmatiese betrekking geyk raak.

Anders as by sintagmatiese leksikale betrekkinge kan daar nie langer onderskei word of die betekenis van die een leksikale item in dié van die ander geënkapsuleer is, of omgekeerd nie. Derhalwe kan die betekenisverhouding of semantiese kohesie nie, soos in die definiens, verantwoord word nie. Die affiniteit van sorg vir baar berus byvoorbeeld nie daarop dat die betekenis van die een leksikale item in die betekenis van die ander opgesluit raak, of omgekeerd nie. Kollokasies soos sorg baar, bose kringloop, klakkeloos napraat, in aanbou, rasend honger, ens. word gelys as geykte sintagmatiese verbindinge waartoe die leksikograaf die gebruiker nóg met 'n verklaring van die betekenis van die individuele komponente, nóg met die neerlê van bepaalde taalreëls, kan lei.

Kollokasies voer as't ware die sintagmatiese leksikale betrekkinge, soos in die definiens blootgelê, tot hul uiterste konsekwensie en toon wat die omvang van dié verskynsel is. Daarom is kollokasies nie 'n herhaling van wat per definisie gesê is nie, maar verteenwoordig hulle eerder 'n uitbouing daarvan.

\subsection{Kollokasies versus voorbeeldsinne}

Sowel kollokasies as voorbeeldsinne (poëme en sitate) word in die woordeboekartikel ingespan om aan te dui hoe ' $n$ bepaalde leksikale item (die lemma) in sintagmatiese kombinasie met ander leksikale items optree.

Kollokasies is eenhede kleiner as sinne en illustreer die tipiese mikro-sintagmatiese konteks waarbinne die lemma optree. Voorbeeldsinne daarteenoor illustreer die makro-sintagmatiese konteks waarbinne die lemma opereer.

Terwyl kollokasies van 'n geykte, stereotiepe sintagmatiese betrekking tussen twee of meer leksikale items getuig, illustreer voorbeeldsinne die losser, meer lukrake, dog steeds natúúrlike sintagmatiese patrone waarbinne die lemma aangetref sal word. Vergelyk die kollokasie verbond sluit met die vrye verbindinge van sluit met deur, juwelekissie, kluis, spens, winkel, ens.

Terwyl dit op die oog af lyk asof kollokasies se funksie in die woordeboekartikel beperk is, vervul voorbeeldsinne 'n komplekse verskeidenheid funksies. Vergelyk in dié verband Gouws (1989: 228-233).

Dit is verder moontlik om kollokatiewe patrone in voorbeeldsinne in te bed, wat die vermoede kan laat ontstaan dat die aangawe van kollokasies oorbodig is. Só 'n redenasie negeer die intrinsieke waarde van elke mikrostruktuurelement binne die groter geheel van die woordeboekartikel.

In die eerste plek is dit gewoon gebruikersvriendelik om kollokasies wat tipiese, vaste taalpatrone weerspieël, as afsonderlike inskrywings aan te bied 
en hul boonop tipografies van voorbeeldsinne af te skei. In deel IX van die Woordeboek van die Afrikaanse Taal, wat na verwagting binne afsienbare tyd gaan verskyn, word kollokasies en voorbeeldsinne deur die simbool en 'n vaste spasie van mekaar geskei. Op dié wyse word aan kollokasies die leksikografiese prominensie verleen wat hul toekom, en terselfdertyd hou sodanige hantering groter vasleggingswaarde vir die gebruiker in. Dit geld veral die tipe kollokasies wat Benson (1985: 61-62) "grammatical collocations" noem. Moedertaalsprekers sal byvoorbeeld die juiste voorsetselkeuse in kollokasies soos die volgende wil kontroleer: verbind tot, beletsel op en gemoeid met.

In die tweede plek kan met behulp van kollokasies 'n groot hoeveelheid waardevolle, tiperende inligting op 'n kompakte wyse weergegee word.

'n Duplisering van inligting waarteen die leksikograaf moet waak, is om 'n bepaalde kollokasie tegelykertyd én as afsonderlike mikrostruktuurelement én as deel van 'n voorbeeldsin aan te gee. Gouws (1989: 232) stel dit duidelik dat sulke duplisering die inligtingsoordrag in 'n woordeboekartikel onnodig verswaar.

Vir die leksikograaf van 'n eentalige, verklarende woordeboek, waarbinne sowel kollokasies as voorbeeldsinne 'n regmatige plek het, is die opname van genoeg voorbeeldmateriaal dikwels 'n probleem. Hy vind meermale dat, nadat hy ' $n$ reeks kollokasies uit die opgetekende gebruiksgevalle geselekteer het, daar weinig materiaal oorbly wat as sitate kan deug. Hy moet dan met die enkele kollokasies volstaan, eerder as om nie-tipiese voorbeeldsinne te gebruik. Die probleem ontstaan meestal in gevalle waar ' $n$ hoë mate van yking tussen die betrokke leksikale items voorkom. Dit is byvoorbeeld slegs in die kollokasie onbewaakte comblik dat onbewaak die betekenis "waarin 'n mens onnadenkend is" aanneem. As die kollokasie onbewaakte oomblik naas die definiens aangegee is, sal die verskaffing van voorbeeldsinne op 'n duplisering van inligting neerkom, tensy hulle belangrike bykomende gebruiksleiding verskaf, byvoorbeeld van grammatiese of sintaktiese aard.

\section{Plasing van kollokasies}

Semanties gesproke sou 'n kollokasie verdeel kon word in 'n outonome basis en 'n afhanklike kollokator. In die kollokasie aandag trek is aandag die outonome basis en trek die kollokator. Die basis aandag kan met 'n reeks kollokators verbind. Vergelyk aandag skenk aan, die aandag vestig op, die aandag bepaal by, die aandag aflei, ens.

Of sodanige verdeling in die leksikografiese praktyk deug, is te betwyfel. Hausmann (1989: 71), Cop (1988: 36) e.a. beweer dat die onderskeid tussen basis en kollokator nuttig is wanneer die leksikograaf oor die plasing van kollokasies moet besluit. Klem word veral gelê op die behoeftes van spesifieke gebruikers en daar word geredeneer dat die aangawe van kollokasies by ó die basis óf die kollokator moet geskied, afhangende daarvan of "text production" 
of "text reception" vir die gebruikers ter sake is.

Vir die moedertaalspreker wat tekste wil produseer en die taal kreatief gebruik, is die basis die vertrekpunt vir dit waaroor hy praat of skryf. Sy waarskynlike vraag sal dus wees watter kollokators met 'n bepaalde ou tonome basis kan verbind. Vir hom moet kollokatiewe patrone gevolglik in die artikel van die basis aangegee word.

Vir die aanleerder van 'n betrokke taal wat tekste wil ontsluit en die taal dekoderend gebruik, sal die waarskynlike vraag wees watter bydrae die basis daartoe lewer om die betekenis van die kollokator te verhelder. Gevolglik verwag die aanleerder kollokasies by elk van die polisemiese onderskeidings van die kollokator.

Hierdie uiteenlopende verwagtings kan aan die hand van die kollokasie ' $n$ rigting inslaan geillustreer word. Die moedertaalspreker wat rigting in 'n bepaalde konteks wil gebruik, wil by die lemma rigting (m.a.w. die basis) die kollokasies ' $n$ rigting inslaan, rigting hou, die rigting aantoon, ens. kan naslaan.

Die aanleerder wil weet hoe die betekenis van inslaan in die kollokasie ' $n$ rigting inslaan deur die basis verhelder word. Gevolglik wil hy by inslaan (m.a.w. die kollokator) naas elke polisemiese waarde inligting oor kollokatiewe patrone hê. Vergelyk die volgende woordeboekartikel uit NW, wat hier gereduseer is tot dit wat vir die doel van die bespreking ter sake is:

inslaan 1. inhamer. 'n Spyker inslaan. 2. stukkend slaan. Die boom, 'n venster inslaan. 3. met ' $n$ slag neerkom. Die weerlig het ingeslaan. 4. indruk maak, byval vind. Die boek, opmerking het ingeslaan. 5. begin gaan, volg. ' $n$ Pad, rigting inslaan. 6. na binne omvou. 'n Mou inslaan.

Gouws (1989: 227) is van mening dat die verdeling basis $x$ kollokator nie uit 'n leksikografiese oogpunt verdedigbaar is nie. Hy beklemtoon kollokasies se funksie as sintagmatiese illustrasiemedium en sê dat die basis se affiniteit vir die kollokator net so belangrik is as die affiniteit van die kollokator vir die basis. ' $n$ Kollokasie soos ' $n$ rigting inslaan kan dus op meer as een plek in die woordeboek as illustrasiemateriaal ingespan word. 'n Rigting inslaan kan as kollokasie in sowel die artikels van rigting as inslaan verskyn.

Die ideale hanteringswyse lê iewers tussen die bogenoemde twee standpunte en het grootliks te make met die mate van yking waaraan die kollokasie onderwerp is. Hoe sterker die kohesie tussen die komponente van die kollokasie, hoe meer geyk of prototipies die kollokasie, hoe wensliker word dit dat die kollokasie in die artikels van elk van die komponente moet verskyn. Hoe swakker die kohesie tussen die komponente, hoe geringer die mate van yking, of hoe minder prototipies die kollokasie, hoe minder wenslik raak dit om die kollokasie in die artikels van beide die komponente te plaas.

Die leksikograaf moet elke leksikale item wat hy as lemma wil opneem, as 'n potensiële basis beskou. Die plasing wat hy uiteindelik kies, moet hy kies aan die hand van ' $n$ betroubare en verteenwoordigende databasis. Die fre- 
kwensie waarmee die leksikale item wat hy wil definieer, in vaste kombinasie met ander leksikale items voorkom (soos uit die databasis blyk), behoort die deurslag te gee. Alleen op dié wyse kan die leksikograaf sy opname en hantering van kollokasies verantwoord en natuurlike taalgebruikspatrone so geloofwaardig as moontlik weergee.

Martin e.a. (1983: 84-87) benadruk die waarde van 'n gerekenariseerde databasis en wys daarop dat dit moontlik is om kollokasies rekenaarmatig te onttrek. Die leksikograaf kan dié gegewens gebruik om statistiese gevolgtrekkings oor die frekwensie van individuele kollokasies te maak en sodoende sy taak aansienlik vergemaklik.

6. Slot

Die leksikograaf van 'n eentalige, verklarende woordeboek probeer die grammatiese sisteem van die taal - en in die besonder die struktuur van die leksikon van dié sisteem - weergee. Om sy weergawe so samehangend as moontlik te maak, moet die leksikograaf noodwendig na vaste verhoudinge tussen leksikale items soek. Deur kollokasies sinvol in ' $n$ woordeboekartikel te integreer, kan die leksikograaf 'n geheelbeeld skep wat vir die gebruiker toeganklik en funksioneel is.

\section{Verwysings}

Aisenstadt, E. 1981. Restricted Collocations in English Lexicology and Lexicography. ITL: Reoiew of Applied Linguistics 53: 53-61.

Benson, M. 1985. Collocations and Idioms. Ilson, R.F. (Red.). 1985: 61-68.

Carstens, A. 1992. Kollokasies: vye verbindings of lekseme? S.A. Tydskrif oir Taalkunde 10 (1): 1-11.

Cop, M. 1988. The Function of Collocations in Dictionaries. Magay, T. en J. Zigány (Reds.). 1988: 35-46.

De Stadler, L.G. 1991. Sintagmatiese leksikale betrekkinge in Afrikaans. Harteveld, P. (Red.). 1991: 60-82.

De Villiers, M. e.a. 19877. Nasionale Woordeboek. Kaapstad: Nasou.

Gouws, R.H. 1989. Leksikografie. Pretoria: Academica.

Harteveld, P. (Red.). 1991. Lexikos. AFRILEX-reeks 1: 1991. Stellenbosch: Buro van die WAT.

Hartmann, R.R.K. (Red.). 1983. Lexicography: Principles and Practice. Londen: Academic Press.

Hausmann, F.J. 1981. Wörterbücher und Wortschatzlemen. Linguistik und Didaktik 45/46: 71-78.

Ilson, R.F. (Red.). Dictionaries, Lexicography and Language Learning. Oxford: Pergamon Press.

Mackin, R. 1978. On Collocations: 'Words Shall Be Known by the Company They Keep'. Strevens, P. (Red.). 1978: 149-165.

Magay, T. en J. Zigány. (Reds.). 1988. BudalEX '88 Proceedings. Budapest: Akadémiai Kiad6. 
Martin, W.J.R., B.P.F. Al en P.J.G. van Sterkenburg. 1983. On the Processing of a Text Corpus: From Textual Data to Lexicographical Information. Hartmann, R.R.K. (Red.). 1983: 77-87.

Odendal, F.F. 19792. Verklarende Handwoordeboek oan die Afrikaanse Taal. Doomfontein: Perskor. Strevens, P. (Red.). 1978. In Honour of A.S. Hornby. Oxford: Oxford University Press. 